\title{
Cathelicidin LL-37
}

National Cancer Institute

\section{Source}

National Cancer Institute. Cathelicidin LL-37. NCI Thesaurus. Code C118292.

A synthetic form of a human antimicrobial peptide (37 amino acids), belonging to the cathelicidin family, with antimicrobial, anti-inflammatory, immunostimulating and potential antineoplastic activities. Upon intratumoral injection of the cathelicidin LL-37, this peptide increases p53 expression, and induces phosphatidylserine externalization, DNA fragmentation, cell cycle arrest and caspase-independent apoptosis-inducing factor (AIF)/ endonuclease G (EndoG)-mediated apoptotic cell death in susceptible cancer cells. This suppresses tumor cell proliferation. LL-37, a protein secreted by bone marrow cells, circulating leukocytes, and various epithelial tissues, plays a crucial role in the innate host immune defense via the regulation of leukocyte chemotaxis and cytokine production; it also promotes wound healing. 